\title{
2010s-19 \\ Assessing the Impact of a Wage Subsidy for Single Parents on Social Assistance
}

\author{
Guy Lacroix
}

Série Scientifique
Scientific Series

\section{Montréal \\ Avril 2010}

(C) 2010 Guy Lacroix. Tous droits réservés. All rights reserved. Reproduction partielle permise avec citation du document source, incluant la notice $\mathbb{C}$.

Short sections may be quoted without explicit permission, if full credit, including (C) notice, is given to the source.
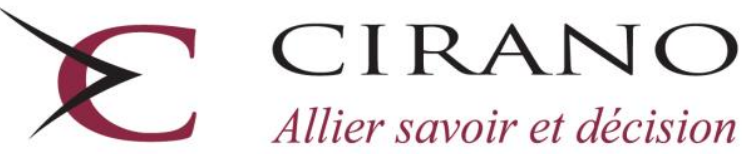

Allier savoir et décision

Centre interuniversitaire de recherche en analyse des organisations 


\section{CIRANO}

Le CIRANO est un organisme sans but lucratif constitué en vertu de la Loi des compagnies du Québec. Le financement de son infrastructure et de ses activités de recherche provient des cotisations de ses organisations-membres, d'une subvention d'infrastructure du Ministère du Développement économique et régional et de la Recherche, de même que des subventions et mandats obtenus par ses équipes de recherche.

CIRANO is a private non-profit organization incorporated under the Québec Companies Act. Its infrastructure and research activities are funded through fees paid by member organizations, an infrastructure grant from the Ministère du Développement économique et régional et de la Recherche, and grants and research mandates obtained by its research teams.

\section{Les partenaires du CIRANO}

Partenaire majeur

Ministère du Développement économique, de l'Innovation et de l'Exportation

\section{Partenaires corporatifs}

Banque de développement du Canada

Banque du Canada

Banque Laurentienne du Canada

Banque Nationale du Canada

Banque Royale du Canada

Banque Scotia

Bell Canada

BMO Groupe financier

Caisse de dépôt et placement du Québec

Fédération des caisses Desjardins du Québec

Gaz Métro

Hydro-Québec

Industrie Canada

Investissements PSP

Ministère des Finances du Québec

Power Corporation du Canada

Raymond Chabot Grant Thornton

Rio Tinto

State Street Global Advisors

Transat A.T.

Ville de Montréal

\section{Partenaires universitaires}

École Polytechnique de Montréal

HEC Montréal

McGill University

Université Concordia

Université de Montréal

Université de Sherbrooke

Université du Québec

Université du Québec à Montréal

Université Laval

Le CIRANO collabore avec de nombreux centres et chaires de recherche universitaires dont on peut consulter la liste sur son site web.

Les cahiers de la série scientifique (CS) visent à rendre accessibles des résultats de recherche effectuée au CIRANO afin de susciter échanges et commentaires. Ces cahiers sont écrits dans le style des publications scientifiques. Les idées et les opinions émises sont sous l'unique responsabilité des auteurs et ne représentent pas nécessairement les positions du CIRANO ou de ses partenaires.

This paper presents research carried out at CIRANO and aims at encouraging discussion and comment. The observations and viewpoints expressed are the sole responsibility of the authors. They do not necessarily represent positions of CIRANO or its partners. 


\title{
Assessing the Impact of a Wage Subsidy for Single Parents on Social Assistance
}

\author{
Guy Lacroix ${ }^{\dagger}$
}

\section{Résumé}

En 2002, le gouvernement du Québec a mis sur pied le programme Action emploi (AE) qui visait à mieux rémunérer le travail des prestataires de l'aide sociale (AS) de longue durée. AE offrait un supplément de revenu généreux pouvant s'échelonner sur une période d'au plus trois ans aux prestataires ayant trouvé un emploi à temps plein à l'intérieur de 12 mois. Le programme a été mis en œuvre pendant une période d'essai d'un an. Sur la base d'une faible évidence empirique, une version légèrement modifiée du programme a été adoptée de façon permanente en mai 2008.

Le document examine l'incidence du programme temporaire en mettant l'accent sur les transitions de la population ciblée sur le marché du travail, à compter de l'année précédant la mise en œuvre du programme jusqu'à la fin de 2005. Nous utilisons un modèle multi-états et multi-épisodes. Afin de prendre en compte l'endogénéité du statut de participation, nous considérons que le programme $\mathrm{AE}$ est un état distinct et nous permettons à des facteurs latents corrélés d'influencer les transitions. Le modèle est évalué par la méthode du maximum de vraisemblance simulée. Nos résultats démontrent que le programme a effectivement augmenté la durée des périodes de sortie de l'AS et diminué légèrement la durée des périodes de recours à l'AS. Le document montre également que la réponse au programme varie considérablement en fonction des caractéristiques individuelles latentes.

Mots clés : assistance sociale, supplément de revenu, modèle de transition multi-états et multi-épisodes.

\footnotetext{
* The author is grateful to participants at the Canadian Labour Market and Skills Researcher Network workshop held in Toronto on November 18 and 192008 for useful comments, and in particular to Dwayne Benjamin and Benoît Delage.

${ }^{\dagger}$ Département d'Economique, Pavillon J.A. De Sève, Québec, Québec, G1K 7P4, Canada.

Tél : 418-656-5122. Fax : 418-656-2707. E-mail : Guy.Lacroix@ecn.ulaval.ca.
} 


\begin{abstract}
In 2002 the Quebec government implemented the "Action Emploi" (AE) program aimed at making work pay for long-term social assistance recipients (SA). AE offered a generous income supplement that could last up to three years to recipients who found a full-time job within twelve months. The program was implemented for a trial period of one year. Based on little empirical evidence, a slightly modified version of the program was implemented on a permanent basis in May 2008.

The paper investigates the impact of the temporary program by focusing on the labour market transitions of the targeted population starting one year before the implementation of the program and up until the end of 2005. We use a multi-state multi-episode model. The endogeneity of the participation status is accounted for by treating AE as a distinct state and by allowing correlated unobserved factors to affect the transitions. The model is estimated by the method of simulated moments. Our results show that AE has indeed increased the duration of Off-SA spells and decreased the duration of SA spells slightly. There is also some evidence that the response to the program varies considerably with unobserved individual characteristics.
\end{abstract}

Keywords: Social assistance, Income supplement, multi-state multi-episode transition model. 


\section{Introduction}

In seeking to alleviate the problems that plague particularly disadvantaged groups when integrating the labour market, governments have traditionally turned to skill enhancing training programs. By enhancing skills, it is hoped that individuals will receive attractive job offers and thus reduce their reliance on transfer programs. Over the past twenty years, the evaluation literature has generally found training programs to have had limited success in achieving these goals [see Heckman, LaLonde and Smith (1999) for a recent and detailed survey and Gilbert, Kamionka and Lacroix (2001) for results pertaining to Canada]. Indeed, only very focused programs targeted at specific groups seem to have had any significant impact on reliance toward support programs.

Many governments have responded to such deceptive results by shying away from traditional training programs and by focusing instead on policies that directly address the relative (un)attractiveness of work. By directly subsidizing wage rates, it is believed many will be induced to accept job offers that would not normally be good alternatives to transfer programs such as social assistance (SA). Inducing individuals to work is motivated by two separate but complementary goals. First, by raising total income such policies may be more effective at addressing poverty than traditional programs. Second, holding a regular job may be conducive to the acquisition of skills and attitudes that are necessary for self-reliance.

Making work pay can be achieved in various ways. In the United States and in the United Kingdom, tax credits and other employment-conditional benefits designed to "make work pay" for low-income workers have been in place for a number of years. ${ }^{1}$ One of the objectives of earned income tax credits is to encourage SA recipients to engage in paid employment through the provision of an earned income supplement that offsets the loss of benefits and/or increased

\footnotetext{
${ }^{1}$ The Earned Income Tax Credit (EITC) program in the US and the Working Families Tax Credit (WFTC) in the UK.
} 
taxation and other costs associated with employment. In Canada, the Working Income Tax Benefit (WITB) was introduced in March 2007. The WITB aims at improving the incentives to work for low-income Canadians and to lower the so-called "welfare wall". The program is a refundable tax credit intended to provide tax relief for eligible working low income individuals and families who are already in the workforce and to encourage others to enter the workforce. To that extent, the program shares many similarities with the EITC and the WFTC.

Prior to implementing the WITB, a policy aiming at helping single parents on social assistance become self-reliant was implemented on an experimental basis. The Self-Sufficiency Project (SSP) was a research and demonstration project that provided a generous, timelimited earnings supplement to SA recipients who found a full-time job and left the rolls. Most evaluations of the SSP conclude that the program has had sizeable impacts on exits from SA [Michalopoulos, Card, Gennetian, Harknett and Robins (2000), Quets, Robins, Paan, Michalopoulos and Card (1999)]. Others have found the program beneficial to children [Morris and Michalopoulos (2000)] and to have had ambiguous results on marital behaviour [Harknett and Gennetian (2001)]. Recent papers that use data for a longer period have found the program to have had at best a temporary effect on SA exits [Card and Hyslop (2005), Brouillette and Lacroix (2010)] or to have had no impact at all once general equilibrium effects are accounted for [Lise, Seitz and Smith (2005)].

Early results from the SSP prompted the Quebec government to implement the "Action Emploi" (AE) program aimed at making work pay for long-term social assistance beneficiaries. Like SSP, AE offered a generous income supplement to those recipients who left SA within twelve months to take a full-time job. Like SSP, recipients were entitled to three years of benefits. But unlike SPP, the supplement was not proportional to earned income. ${ }^{2}$ The AE

\footnotetext{
${ }^{2}$ It has been argued that linking the subsidy to earned income may result in self-selection into the program. See, e.g., Brouillette and Lacroix (2010).
} 
program was implemented on an experimental basis for a single year. ${ }^{3}$ Very little research has looked into the impact of the program on the employment history of the targeted population. Yet, based on little empirical evidence a slightly modified version of the program was implemented on permanent basis in May 2008.

The unique features of AE (universal accessibility, large-scale program, substantial financial incentives, etc.) offer a unique opportunity to document the impact of a SSP-like program on the response of long-term heterogeneous groups of SA recipients in a "real-world" setting. Unlike SSP, though, eligibility is not randomly determined. Instead the recipients in our sample were all eligible for $\mathrm{AE}$ at the time of its implementation and participation in the program is likely the result of a decision that depends on observable and unobservable individual characteristics. Consequently, a simple comparison between AE and Non-AE recipients will likely produce a biased estimate of the mean program impact on the duration of SA and Off-SA spells (so-called "Average treatment effect"). Further, it might be more relevant to focus on the net impact of the program on the labour market history of those who actually took-up AE (so-called "Treatment effect on the treated") because the take-up rate was relatively low (approximately $7.4 \%$ of the eligible population). On the other hand, focusing on the program impact on AE participants raises difficult methodological issues because participants may constitute a strongly self-selected group whose behaviour may be unrepresentative of what would be observed were the "average" SA recipient to participate in AE. Fortunately these difficulties can be addressed with the appropriate econometric techniques. We thus use a multi-state multi-episode transition model. The endogeneity of the participation status is accounted for by treating $\mathrm{AE}$ as a distinct state and by allowing correlated unobserved factors to affect the observed transitions. We focus on the transitions on the labour market starting one year before the implementation of the program and up until the end of 2005.

\footnotetext{
${ }^{3}$ Those who qualified within the 12 -month qualification phase were entitled to three years of benefits, i.e. until December 2005 at the latest.
} 
Our results show that AE has indeed increased the duration of Off-SA spells and decreased the duration of SA spells slightly. There is also some evidence that the response to the program varies considerably with unobserved individual characteristics. Inasmuch as our results reflect the true program impact, the Quebec government was probably justified in implementing the program on a permanent basis as it did in May 2008.

The paper is organized as follows. The next section presents the Action Emploi program. Sample statistics and prima facie evidence on the impact of the program are also presented. Section 3 briefly sketches the econometric approach. In Section 4 we present the econometric results. The relationship between the parameter estimates and the duration in a given state a highly non-linear. Consequently, we conduct a series of simulations ease their interpretation. Finally, Section 5 concludes the paper.

\section{The Action Emploi Program}

The AE program was implemented on December $1^{\text {st }} 2001$. To be eligible for AE, SA recipients had to have claimed welfare benefits for at least 36 out of the last 45 months. They also had to find a full-time job (130 hours per month) and earn a gross wage that was at least equivalent to the minimum wage rate. The self-employed were also eligible. To qualify, their net earnings had to be at least equivalent to a full-time minimum wage job. ${ }^{4}$ Individuals could register and file a claim at any time between December $1^{\text {st }} 2001$ and November $30^{\text {th }} 2002.5$ Those who did not meet the hours or income conditions in any given month kept their entitlement during a grace period that lasted up to four months. They were automatically disqualified if

\footnotetext{
${ }^{4}$ The thresholds were changed twice due to changes in the provincial minimum wage rate:

- 910\$: December $1^{\text {st }} 2001$ - September $30^{\text {th }} 2002(130 \times 7.00 \$)$.

- 936\$: October $1^{\text {st }} 2002$ - January $31^{\text {st }} 2003(130 \times 7.20 \$)$.

- $949 \$$ : February $1^{\text {st }} 2003-(130 \times 7.30 \$)$.

As long as the employment requirements are met, the income supplement is paid out, irrespective of earnings.

${ }^{5}$ Once registered, individuals had to file a monthly report that stated their employment status, their earnings, if any, and the total number of hours worked.
} 
they did not meet the requirement during the fourth month. ${ }^{6}$ Contrary to SSP, the benefits were not tied to monthly earnings. ${ }^{7}$ Instead they were set to $390 \$ /$ month during the first year of eligibility, and to $260 \$ /$ month and $130 \$ /$ month in the second and third year of eligibility, respectively. ${ }^{8}$

In the months leading to the implementation of the program, SA recipients were sent a letter along with their benefits that detailed the main parameters of the program. They were also reminded about the program whenever they met with their caseload worker. Further, between June 2001 and September 2002 all those who had left the rolls and who met the cumulative stay requirement were sent another letter that reminded them of the existence of the program. Finally, another letter was sent to all SA recipients with similar cumulative stays in October 2002 to inform them that they had only 2 months left to file a claim. Despite all these efforts, only $7.4 \%$ of the eligible population claimed the income supplement. These were paid out as early as January $1^{\text {st }} 2002$. Figure 1 below shows the two main periods of the program. The firsts to register (early December 2001) could receive income supplements until the end of November 2004. Those who registered last (end of November 2002) could receive the supplement until the end of November 2005.

\subsection{Characteristics of the AE participants and Empirical Evidence}

According to government reports, 13,244 SA recipients registered for AE between December 2001 and November 2002. Table 1 below shows the main characteristics of the participants. The majority are either singles or single parents. They are relatively poorly educated. Over

\footnotetext{
${ }^{6}$ This a major difference with SSP. Indeed, SSP participants keep their entitlement during the 36-month window, irrespective of working or not. With Action Emploi, entitlement if definitely lost after four months of inactivity.

${ }^{7}$ In the SSP, the benefits are roughly equivalent to: $B=0.50 \times(37,500 \$-w h)$, where $w$ is the hourly wage rate and $h$ is the annual hours of work. Consequently the benefits are a decreasing function of earnings. This may generate serious self-selection problems in the experiment. See Brouillette and Lacroix (2010).

${ }^{8}$ This is more or less equivalent to $43 \%, 28 \%$ and $14 \%$ of a full-time minimum wage job in each of the entitlement years.
} 
Figure 1: Action Emploi - Timeline

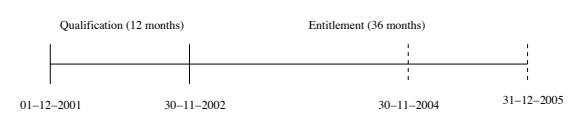

$75 \%$ of the participants have earned at most a high-school degree. The last panel of the table also indicates that the vast majority have very little attachment to the labour market. Nearly $44 \%$ of the participants have had cumulative stays on SA that lasted between 4 and 10 years prior to their participation, and over $48 \%$ of them have had cumulative stays of over 10 years.

The empirical analysis is based on the administrative records of the Ministère de l'emploi et de la Solidarité sociale du Québec (MESS). The data span the period from January 2000 until December 2005. The files include detailed information on household type, number of children, region of residence, gender, schooling, birthplace, and monthly indicators on SA/AE participation.

We focus exclusively on single parents to allow a comparison with SSP. The files show that over 51,118 single parents satisfied the requirements for $\mathrm{AE}$ at the time of its implementation. In all, 3,807 individuals qualified for benefits. ${ }^{9}$ The main statistical features of our sample are reported in Table 2. Both groups are composed almost entirely of women born in Canada and

\footnotetext{
${ }^{9}$ There are 4,118 single parents in the administrative files. A total of 311 observations are omitted due to missing data.
} 
Table 1: Characteristics of the AE participants

\begin{tabular}{lrr}
\hline Type of household & \# individuals & Proportion \\
Singles & 5,984 & 45.2 \\
Single parents & 4,118 & 31.3 \\
Couples, no children & 727 & 5.5 \\
Couples, children & 2,271 & 17.1 \\
Unknown & 144 & 1.1 \\
Schooling & & \\
Primary & 660 & 5.0 \\
Secondary (incomplete) & 6,167 & 46.6 \\
Secondary (completed) & 3,495 & 26.4 \\
Post-secondary & 1,302 & 9.8 \\
University & 792 & 6.0 \\
Unknown & 828 & 6.2 \\
Cumulative months on SA & & \\
36-47 & 921 & 7.0 \\
48-119 & 5,847 & 44.1 \\
120+ & 6,342 \\
Unknown & \multicolumn{2}{c}{134} \\
\hline Source: Direction générale & la recherche, & \multicolumn{1}{c}{ de } \\
l'évaluation et de la statistique, MSSS, 2003. &
\end{tabular}

who have approximately the same number of children. Participants are slightly younger and more educated. Likewise, the geographical distribution of the two groups is similar, albeit the fact that proportionately fewer participants live in the Greater Montreal area.

Despite the two groups being observationally similar, the differences between the two groups are nevertheless statistically significant. Table 3 reports the results of fitting a simple probit regression on $\mathrm{AE}$ participation. It turns out most parameter estimates are highly statistically significant and corroborate the findings of Table 2. In particular, participation increases with education and decreases with age. Likewise, participation rates are everywhere higher than in the metropolitan area of Montreal. These results suggest that participation in AE must be conditioned on observed characteristics.

\subsection{Prima facie evidence on the impact of AE}

Individual histories are derived from administrative records. Our analysis starts in January 2000, one year prior to the implementation of AE. Four different states on the labour market 
Table 2: Sample Characteristics

\begin{tabular}{|c|c|c|c|c|}
\hline \multirow[t]{3}{*}{ Variable } & \multicolumn{2}{|c|}{$\overline{\mathrm{AE}}$} & \multicolumn{2}{|c|}{ Non-AE } \\
\hline & Mean & Std & Mean & Std \\
\hline & & Dev & & Dev \\
\hline Age & 33.712 & 7.772 & 35.107 & 9.647 \\
\hline Education & 11.054 & 2.236 & 10.374 & 2.590 \\
\hline Number of children & 1.586 & 0.870 & 1.520 & 0.871 \\
\hline Gender $(1=$ Female $)$ & 0.879 & 0.326 & 0.870 & 0.337 \\
\hline Born in Canada & 0.816 & 0.387 & 0.816 & 0.387 \\
\hline \multicolumn{5}{|l|}{ Region of residence } \\
\hline Bas St-Laurent & 0.025 & & 0.019 & \\
\hline Saguenay - Lac St-Jean & 0.040 & & 0.039 & \\
\hline Capitale-Nationale & 0.093 & & 0.070 & \\
\hline Mauricie & 0.078 & & 0.067 & \\
\hline Estrie & 0.049 & & 0.033 & \\
\hline Montréal & 0.179 & & 0.255 & \\
\hline Outaouais & 0.038 & & 0.044 & \\
\hline Abitibi-Témiscamingue & 0.022 & & 0.022 & \\
\hline Côte-Nord & 0.018 & & 0.015 & \\
\hline Nord du Québec & 0.002 & & 0.003 & \\
\hline Gaspésie - Iles de la Madeleine & 0.029 & & 0.020 & \\
\hline Chaudière -Appalaches & 0.029 & & 0.027 & \\
\hline Laval & 0.024 & & 0.030 & \\
\hline Lanaudière & 0.062 & & 0.046 & \\
\hline Laurentides & 0.071 & & 0.052 & \\
\hline Montérégie & 0.150 & & 0.141 & \\
\hline Centre du Québec & 0.011 & & 0.007 & \\
\hline Montréal banlieue & 0.083 & & 0.109 & \\
\hline Number of observations & 3807 & & 47311 & \\
\hline
\end{tabular}


Table 3: Probit Regression: AE Participation

\begin{tabular}{|c|c|c|c|}
\hline Variable & $\begin{array}{c}\text { Marginal } \\
\text { Effect } \\
(\partial \Phi / \partial X)\end{array}$ & T-Stat & P-Value \\
\hline Age & -0.001 & -9.06 & 0.000 \\
\hline Education & 0.008 & 16.48 & 0.000 \\
\hline Number of Children & 0.007 & 5.69 & 0.000 \\
\hline Gender (1=Female) & 0.005 & 1.58 & 0.114 \\
\hline Born in Canada & -0.003 & -0.91 & 0.362 \\
\hline Region of residence (Montreal om & & & \\
\hline Bas St-Laurent & 0.060 & 6.00 & 0.000 \\
\hline Saguenay - Lac St-Jean & 0.032 & 4.53 & 0.000 \\
\hline Capitale-Nationale & 0.053 & 9.38 & 0.000 \\
\hline Mauricie & 0.042 & 7.40 & 0.000 \\
\hline Estrie & 0.063 & 8.24 & 0.000 \\
\hline Outaouais & 0.017 & 2.55 & 0.011 \\
\hline Abitibi-Témiscamingue & 0.029 & 3.19 & 0.001 \\
\hline Côte-Nord & 0.050 & 4.46 & 0.000 \\
\hline Nord du Québec & -0.000 & -0.01 & 0.995 \\
\hline Gaspésie - Iles de la Madeleine & 0.069 & 7.09 & 0.000 \\
\hline Chaudière -Appalaches & 0.036 & 4.34 & 0.000 \\
\hline Laval & 0.008 & 1.03 & 0.305 \\
\hline Lanaudière & 0.056 & 8.43 & 0.000 \\
\hline Laurentides & 0.056 & 8.84 & 0.000 \\
\hline Montérégie & 0.032 & 7.48 & 0.000 \\
\hline Centre du Québec & 0.060 & 3.96 & 0.000 \\
\hline Montréal banlieue & 0.004 & 0.88 & 0.379 \\
\hline Log likelihood & \multicolumn{3}{|c|}{$-13,230.965$} \\
\hline
\end{tabular}


can be determined from the data: (1) Off-SA; (2) SA; (3) AE; (4) GP. Off-SA simply refers to not being on the rolls. Individuals in this situation may be employed, ineligible for SA benefits, or may be collecting employment insurance benefits. SA and AE are mutually exclusive states. Finally GP refers to the grace period, i.e. to AE participants who are unemployed in a given month but who are still eligible for benefits.

Table 2 has shown that participants and non-participants are observationally quite similar. We further the comparison between the two groups by focusing on their behaviour on the labour market. Figure 2 depicts the survival rates in SA and Off-SA in the year that proceeded the implementation of AE. Because the program was announced in the March 2000 budget it is unlikely that SA recipients have modified their behaviour to meet the program's requirement although this possibility can not be ruled out completely. The spells are left-truncated as of January 2000. Likewise, spells that last more than 13 months are truncated and treated as censored. Interestingly, the figure shows important differences. Indeed, recipients who eventually participate in AE have much lower survival rates Off-SA (and thus shorter spells) than those who never participate. On the other hand, their survival rates in SA are slightly smaller. The difference between the two curves increases around the 10th month, presumably because some leave welfare to enter AE.

Figure 3 depicts the survival rates for spells that begin after January 2001. For AE participants, only the spells that begin after definitely exiting the program are considered. ${ }^{10}$ Interestingly, the survival rates of participants in Off-SA are now higher than those of the non-participant. Likewise, the difference in the survival rates in SA between the two groups has increased dramatically. ${ }^{11}$

\footnotetext{
${ }^{10}$ The average cumulative duration in $\mathrm{AE}$ is 18.4 months. Nearly half the participants spend less than 12 months in the program.

${ }^{11}$ Log-rank tests strongly reject equality of the survival curves in each figure.
} 
Figure 2: Survival Functions, Year Before Implementation of $\mathrm{AE}^{\dagger}$
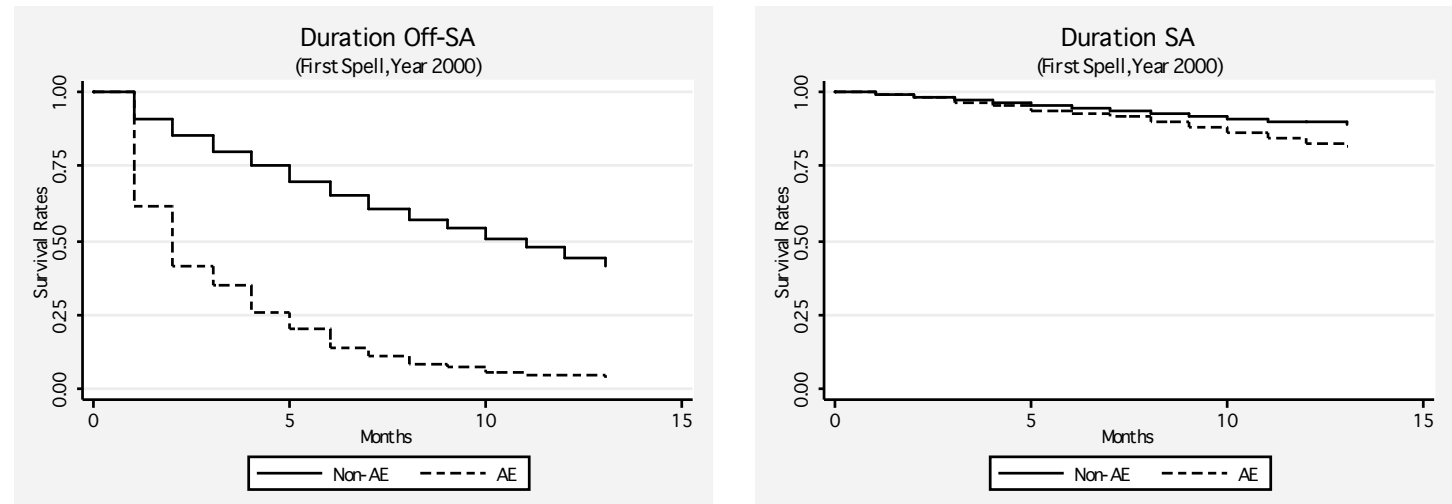

${ }^{\dagger}$ Spells that last more than 13 months are censored.

Based on these figures it would be tempting to conclude that the AE program has had a strong impact on the duration of both SA and Off-SA spells. Of course, the above figures do not account for the fact that participants may have different observed characteristics. Nor do they account for the potential selection bias into AE. Indeed, it may be that those who took-up AE were more motivated to leave SA. Hence we should not expect a SA recipient chosen at random to benefit as much from $\mathrm{AE}$ as what the figures suggest. Only an in-depth econometric analysis can measure precisely the contribution of the AE program on the relative attachment of participants to the labour market. In particular, a multi-state multi-episode model will allow us to determine the "steady-state" proportion of time spent on and off SA for participants and non-participants alike [see Eberwein, Ham and LaLonde (2002) and Bonnal, Fougère and Sérandon (1997)]. 
Figure 3: Survival Functions, Intermediate Spells ${ }^{\dagger}$
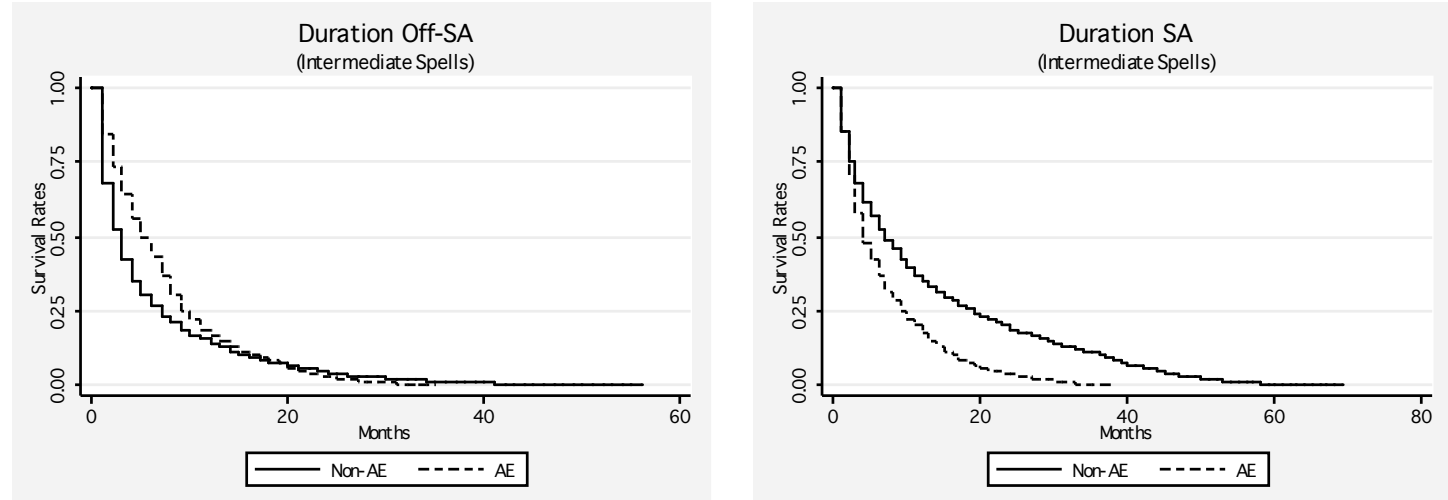

${ }^{\dagger}$ For Non-AE, spells begin after year 2000. For AE spells begin after their participation has ended.

\section{The econometric model}

Multi-state multi-episode models are well suited to address the potential problem of endogenous participation in AE. ${ }^{12}$ Furthermore, once the entitlement phase ends, and given participation was properly modelled, the subsequent transitions can be conditioned on past participation. ${ }^{13}$ The model can thus determine the extent to which post-program durations on and off SA are affected by AE. The identification of the AE effect rests on the presence of a control group composed of those who did qualify but did not participate.

Each individual in our sample qualified for $\mathrm{AE}$ at the time of its implementation in December 2001. Figure 4 below depicts the work history of hypothetical non-participants and participants, respectively. The dashed vertical lines delimit the period of observation. The left hand-side figure shows that a typical non-participant will be observed in the SA (or Off-

\footnotetext{
${ }^{12}$ Despite the fact that over 3,807 single parents participated, as many as 47,311 did not. Observed and unobserved differences could be important determinants of participation. In particular, only those who met their caseload worker or who spent time reading the relevant documentation may have been aware of the existence of the program. These individuals may also differ in other aspects.

${ }^{13}$ The transitions $\mathrm{SA} \rightarrow \mathrm{Off}-\mathrm{SA}$ and Off-SA $\rightarrow \mathrm{SA}$ will thus be conditioned on past AE participation through dummy variables. These will shift the hazard functions up or down in a non-linear fashion. See equation (5).
} 
SA) state at the beginning of January 2000. The spell is left-censored as we only observe the residual duration that lasts up until June 2001, say. She then leaves SA for approximately 33 months, and then returns to SA until the end of December 2005. All spells are right censored in December 2005. The typical participant exhibits similar transitions. Upon leaving SA she enters AE for approximately 10 months. She loses her job and moves into the SA-AE state for approximately 3 months. Upon finding a new job, she returns to AE for a spell of about 2 years. She next returns to SA for a short period and moves into Off-SA until the end of the period of observation.

Figure 4: Employment history of a hypothetical Non-AE \& AE
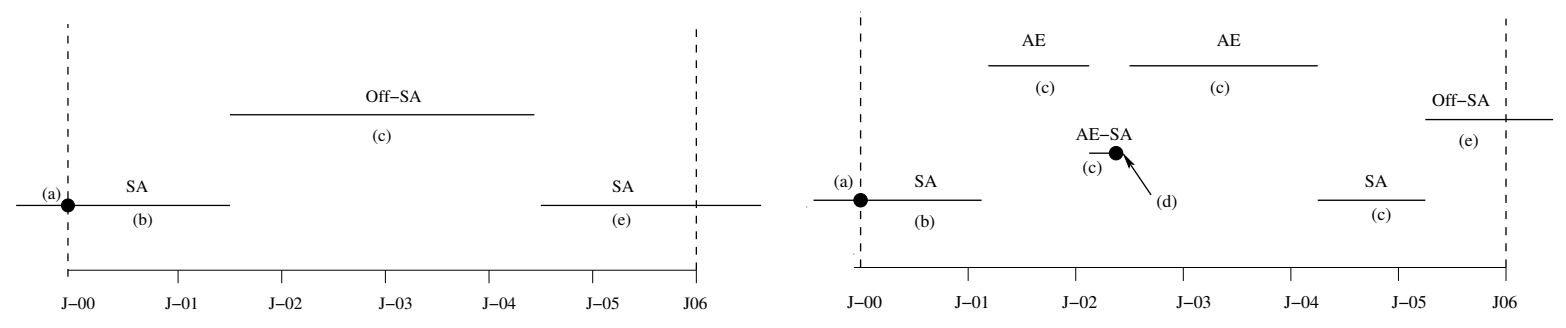

\subsection{Modelling individual histories}

The figure illustrates the complexity of individual histories. It also underscores the many statistical challenges that must be tackled. Indeed, the potential self-selectivity into AE must be accounted for. In addition, the model must take into account the finite duration of both the AE program and the grace period (GP). In both cases, termination involves a discontinuity in the exit rate and a discrete decision to move into a new state. Finally, left-censored spells must be treated carefully. Different alternatives exist but none are entirely satisfactory. We could for instance focus on the transitions that occur after the implementation of the AE program. This would solve the problem for the participants but not for the non-participants. Instead 
we define separate hazard functions for left-censored spells and we model the initial condition explicitly [see Heckman and Singer (1984) and Ham and LaLonde (1996)].

The likelihood function builds on individual histories such as those depicted in Figure 4. Let $m$ denote the number of episodes for a given individual. Each episode is characterized by its duration and the state that succeeds it (destination state). Write the endogenous variables as $r_{0},\left(\delta_{1}, r_{1}\right),\left(\delta_{2}, r_{2}\right), \ldots,\left(\delta_{m} r_{m}\right)$, where $r_{0}$ is the initial state, $\delta_{j}$ is the duration of the $j^{\text {th }}$ episode and $r_{j}$ is the destination state that brings it to an end, $j=1, \ldots, m$.

We use a conventional multi-state multi-episode model that specifies the joint distribution of the continuous and discrete variables [see Lawless (2003), Mealli and Pudney (2003)]. More precisely, let $f\left(\delta_{j}, r_{j} \mid X_{j}, \nu\right)$ be the joint density of the duration and destination state of the $j^{\text {th }}$ spell. The density is conditional on a vector of observed characteristics which may include earlier state and duration variables to allow for lagged state dependence. ${ }^{14}$ The variables are all spell-specific and are assumed constant over the duration of a given spell. The term $\nu$ is a vector of unobserved individual random effects that are constant over time. This constancy is likely to generate serial dependence in the sequence of episodes.

We will write the likelihood function in a chronological fashion starting from January 2000 and up until December 2005. Start first with state in which an individual is initially observed. Conditional on vectors of observed and unobserved characteristics, $X_{0}, \nu$, respectively, the probability of observing $r_{0}$ may be written as $\operatorname{Pr}\left(r_{0} \mid X_{0}, v\right)$. This probability corresponds to point (a) in Figure $4 .{ }^{15}$ Under our sampling scheme, the first spell is truncated from the left [segment (b) in the figure]. In the event the episode ends prior to December 2005, the joint density of $\left(\delta_{1}, r_{1}\right)$ can be written as $f^{*}\left(\delta_{1}, r_{1} \mid X_{1}, \nu\right)$. If the episode is not interrupted, then the spell is said to be right-censored and both the duration and the destination state are unknown.

\footnotetext{
${ }^{14}$ See Doiron and Gorgens (2008) for a recent and in-depth analysis of state dependence in labour market outcomes.

${ }^{15}$ In our data, the initial state is either SA or Off-SA.
} 
The distribution of such a spell is characterized by a survivor function, $S^{*}\left(\delta_{1} \mid X_{1}, \nu\right)$, which gives the conditional probability that the spell lasts at least $\delta_{1}$ months. ${ }^{16}$

Subsequent spells correspond to segments (c) in Figure 4. The density function of such spells is allowed to differ from the density of the first spell. We thus write the joint density of $\left(\delta_{j}, r_{j}\right)$ as $f\left(\delta_{j}, r_{j} \mid X_{j}, \nu\right), j=2, \ldots, m-1$. A special feature of the AE program is the so-called "grace period". Recall that AE participants are allowed not to meet the program's employment requirement for a maximum of 4 months, after which eligibility is lost and a transition into either Off-SA or SA must be made. This situation is identified as point (d) in the figure. We must thus allow for a discontinuity in the destination state probabilities once the grace period has ended. The transition model operates normally until the maximum duration is reached, at which point a separate discrete model comes into play. We will write $\operatorname{Pr}\left(r=l \mid \delta_{j}=4, X, \nu\right), l=$ Off-SA, SA.

Finally, the last observed spell is necessarily still in progress in December 2005 [segment (e) in the figure]. Its distribution is thus characterized by a survivor function, $S\left(\delta_{m} \mid X_{m}, \nu\right)$, that may be functionally different from $S^{*}\left(\delta_{1} \mid X_{1}, \nu\right)$. Conditional on the observed covariates, $X=\left\{X_{0}, X_{1}, X_{2}, \ldots, X_{m}\right\}$, and the unobserved characteristics, $\nu$, the joint distribution of $r_{0},\left(\delta_{1}, r_{1}\right),\left(\delta_{2}, r_{2}\right),\left(\ldots, \delta_{m}, r_{m}\right)$, is given by:

$$
\begin{aligned}
f(\cdot)= & \underbrace{\operatorname{Pr}\left(r_{0} \mid X_{0}, \nu\right)}_{(a)} \times \underbrace{\left\{f^{*}\left(\delta_{1}, r_{1} \mid X_{1}, \nu\right)^{1-c} S^{*}\left(\delta_{1} \mid X_{1}, \nu\right)^{c}\right\}}_{(b)} \times \\
& {[\prod_{j=1}^{m-1} \underbrace{f\left(\delta_{j}, r_{j} \mid X_{j}, \nu\right)} \times \underbrace{\operatorname{Pr}\left(r=l \mid \delta_{j}=4, X_{j}, v\right)^{G P_{j}}}] \times \underbrace{S\left(\delta_{m} \mid X_{m}, \nu\right)}, }
\end{aligned}
$$

$(c)$

$(d)$

\footnotetext{
${ }^{16}$ Over $46 \%$ of SA spells in January 2000 were still ongoing in December 2005.
} 
where $G P_{j}=1$ if the state $j$ corresponds to the censored grace period and 0 otherwise. Since the error terms $\nu$ are unobserved, we must specify a distribution function, $G(\nu)$, say, to make equation (1) an estimable econometric model. The error terms can be integrated out and the estimation proceeds by maximizing the following log-likelihood function:

$$
\begin{aligned}
\ln L= & \sum_{i=1}^{N} \ln \left\{\int \operatorname{Pr}\left(r_{0} \mid X_{0}, \nu\right) f^{*}\left(\delta_{1}, r_{1} \mid X_{1}, \nu\right)^{1-c} S^{*}\left(\delta_{1} \mid X_{1}, \nu\right)^{c} \times\right. \\
& \left.\prod_{j=1}^{m-1} f\left(\delta_{j}, r_{j} \mid X_{j}, \nu\right) \operatorname{Pr}\left(r=l \mid \delta_{j}=4, X_{j}, v\right)^{G P_{j}} S\left(\delta_{m} \mid X_{m}, \nu\right) d G(\nu)\right\},
\end{aligned}
$$

where the suffix $i=1, \ldots, N$ indexes the individuals in the sample.

The main problem with the estimation of the likelihood function (2) is the computation of the multi-dimensional integral over the domain of $\nu$. As is now customary, we approximate the integral by an average over $H$ pseudo-random deviates. Let $\hat{l}_{i}\left(\nu^{h}\right)$ denote the contribution of individual $i$ to the $\log$-likelihood function for a given draw $\nu^{h}$. The approximate $\log$-likelihood we maximize is the following:

$$
\widehat{\ln L}=\sum_{i=1}^{N} \ln \left(\frac{1}{H} \sum_{h=1}^{H} \hat{l}_{i}\left(\nu^{h}\right)\right)
$$

where $H$ is the number of draws. The maximization of the simulated likelihood function yields consistent and efficient parameter estimates if $\sqrt{N} / H \rightarrow 0$ when $H \rightarrow+\infty$ and $N \rightarrow+\infty$ [see Gouriéroux and Monfort $(1991,1996)]{ }^{17}$ The next sections provide a detailed discussion about the likelihood function and the estimation procedure. They can be omitted as they are not essential to the understanding of the empirical results.

\footnotetext{
${ }^{17}$ While the literature has established that $H=20$ appears adequate [see Laroque and Salanié (1993), Kamionka (1998)], we have chosen $H=100$ even though the slope parameters are relatively insensitive to the number of draws we use.
} 


\subsection{Transition intensity functions}

The transition components of the model $[f(\cdot)$ and $S(\cdot)]$ are based on origin and destinationspecific transition intensity functions. These give the instantaneous probability of exit to a specific destination at a particular time conditional on no previous exit having occurred. Thus, for a given episode spent in state $k$ the $l^{\text {th }}$ transition intensity function $\lambda_{k l}(t \mid X, \nu)$ if given by:

$$
\operatorname{Pr}(r=l, \delta \in(t, t+d t) \mid \delta \geq t, X, \nu)=\lambda_{k l}(t \mid X, \nu) d t
$$

where $\mathrm{X}$ is spell-specific as mentioned above. The administrative data is constructed in such a way that a given episode can never be observed to be followed by an episode of the same type. The joint probability of exit route $r$ and duration $\delta$ is given by:

$$
f(\delta, r \mid X, \nu)=\lambda_{k r}(\delta \mid X, \nu) \exp \left[-\sum_{l \neq k} I_{k l}(\delta \mid X, \nu)\right]
$$

where $I_{k l}(\delta \mid X, \nu)$ is the $(k, l)^{\text {th }}$ integrated hazard:

$$
I_{k l}(\delta \mid X, \nu)=\int_{0}^{\delta} \lambda_{k l}(t \mid X, \nu) \mathrm{d} t
$$

Ideally the transition intensity functions should we as flexible as possible. Non-parametric specifications are the most flexible but they entail many parameters. They are useful when studying single spells data. But in our context they simply are not practical. Instead we use the log-logistic form. The main advantage of this specification is that the shape of the hazard function need not be monotone in duration. It is given by the following expression:

$$
\lambda_{k l}=\frac{\exp \left(X_{k} \beta_{k l}+\nu_{l}\right) \kappa_{k l} \alpha_{k l} t^{\alpha_{k l}-1}}{1+\exp \left(X_{k} \beta_{k l}+\nu_{l}\right) \kappa_{k l} t^{\alpha_{k l}}}
$$


where $X_{k}$ is a row-vector of observable characteristics (including possibly past AE participation), $\beta_{k l}$ is an appropriately dimensioned origin-destination-specific vector of parameters, and $\kappa_{k l}$ and $\alpha_{k l}$ are also origin-destination-specific parameters. ${ }^{18}$ The associated integrated hazard function is given by:

$$
I_{k l}=\ln \left(1+\exp \left(X_{k} \beta_{k l}+\nu_{k l}\right) \kappa_{k l} t_{k l}^{\alpha}\right)
$$

The associated survivor function is consequently given by:

$$
S_{k l}\left(\delta \mid X_{k}, \nu\right)=\frac{1}{1+\exp \left(X_{k} \beta_{k l}+\nu_{l}\right) \kappa_{k l} t^{\alpha_{k l}}}
$$

Recall from the likelihood function (2) that the density functions of the initial and subsequent spells are allowed to differ. This is achieved by estimating two separate sets of parameters, $\alpha_{k l}^{*}, \kappa_{k l}^{*}, \beta_{k l}^{*}$ and $\alpha_{k l}, \kappa_{k l}, \beta_{k l}$ that each correspond to $f^{*}(\cdot)$ and $f(\cdot)$, respectively.

\subsection{Initial state and Grace period}

Individuals in our sample are observed either in state Off-SA or SA in January 2000. We model the initial state indicator as a binomial logit structure:

$$
\operatorname{Pr}\left(r_{0}=S A \mid X_{0}, \nu\right)=\frac{\exp \left(X_{0} \gamma_{0}+\nu\right)}{1+\exp \left(X_{0} \gamma_{0}+\nu\right)}
$$

where $\gamma_{0}$ is an appropriately dimensioned vector of parameters. The parameter vector associated with Off-SA is implicitly normalized to zero. The probability of the initial state is thus correlated to the other states through the unobserved heterogeneity term.

The discussion surrounding the likelihood function stressed that the model needed to account for the finite duration of the grace period. We introduce a discontinuity in the destination

\footnotetext{
${ }^{18}$ Gritz (1993) also uses a log-logistic specification.
} 
state probabilities through a logistic model. ${ }^{19}$ For an exhausted GP spell only transitions into SA or Off-SA can be observed. The probability of observing state SA is also written as a logistic function:

$$
\operatorname{Pr}(r=S A \mid X, \nu)=\frac{\exp (X \gamma+\nu)}{1+\exp (X \gamma+\nu)}
$$

This specification is identical to the initial condition logit. As with the initial condition specification, the parameter vector associated with Off-SA is implicitly normalized to zero. ${ }^{20}$

\subsection{Unobserved heterogeneity}

The next issue that must be addressed to make the model amenable to estimation is to specify the manner in which unobserved heterogeneity enters the above specification. Most applications rely on the work of Heckman and Singer (1984) and approximate arbitrary continuous distributions using a finite number of mass points [see Gritz (1993), Ham and Rea (1987), Doiron and Gorgens (2008)]. A number of recent papers use flexible specifications that allow the heterogeneity terms to be correlated across states [see Ham and LaLonde (1996), Eberwein et al. (2002)]. These specifications are sometimes referred to as single or double-factor loading distributions and are also based on a finite set of mass points.

Our setting involves four distinct states. In addition, we distinguish between complete and incomplete SA and Off-SA spells, we control for the initial condition and allow for a discontinuity in the GP state. The above approach is impractical in our setting as it would involve too many parameters. Instead we use a two-factor specification, where each of the two random effects are constant over time and linked to a particular state of origin. To fix ideas, let $\nu=\left(\nu_{1}, \ldots, \nu_{K}\right)$ be a vector of unobserved heterogeneity variables, with $\nu_{k}$ an origin-specific

\footnotetext{
${ }^{19}$ Mealli, Pudney and Thomas (1996) were the first to propose to modify the model in this manner to account for an exogenous limit on duration.

${ }^{20}$ In principles we should also allow for a discrete change in the transition probabilities once AE comes to an end at 36 months. Because all such spells move into Off-SA there is no need to modify the density function.
} 
component $(k=1, \ldots, 4)$. Ideally, the joint distribution of the unobserved heterogeneity terms should not be independent. Consider a two-factor loading model [see Van den Berg (1997)] such that

$$
\nu_{k}=\exp \left(\theta_{k}^{1} \xi_{1}+\theta_{k}^{2} \xi_{2}\right)
$$

where $\nu_{k}$ is the random effect associated with state $k, \theta_{k}^{1}$ and $\theta_{k}^{2}$ are loading factors for state $k$, and $\xi_{1}$ and $\xi_{2}$ are independent random draws from the standard normal distribution. ${ }^{21}$ To insure identification of the parameters, we impose $\theta_{k}^{1}=1, k \geq 2$ and $\theta_{1}^{2}=1$. It can easily be shown that the correlation between $\log \left(\nu_{k}\right)$ and $\log \left(\nu_{l}\right)$ is given by:

$$
\rho_{k l}=\frac{\theta_{k}^{1} \theta_{l}^{1}+\theta_{k}^{2} \theta_{l}^{2}}{\sqrt{\left(\theta_{k}^{1}\right)^{2}+\left(\theta_{k}^{1}\right)^{2}} \sqrt{\left(\theta_{k}^{2}\right)^{2}+\left(\theta_{k}^{2}\right)^{2}}} .
$$

A positive correlation between states $k$ and $l$ indicates that unobserved characteristics that favour a (conditionally on $X$ ) high exit rate from state $k$ are likely to favour a high exit rate from state $l$ as well.

\section{Estimation Results}

The model involves numerous parameter estimates. Indeed, there are as many as 12 different transitions to consider (first spell and subsequent spells). Each one comprises a vector of slope parameters $\left(\beta_{k l}\right.$ or $\left.\beta_{k l}^{*}\right)$ and 2 parameters that describe the shape of the hazard functions $\left(\alpha_{k l}\right.$ and $\kappa_{k l}$ or $\alpha_{k l}^{*}$ and $\kappa_{k l}^{*}$ ). In addition two vectors are estimated to control for the potential endogeneity of the initial spell and for the discrete jump in the transition that occurs once the grace period has ended. Finally, the loading factors, $\theta_{k}^{1}, \theta_{k}^{2}$, are necessary to account for the

\footnotetext{
${ }^{21}$ A similar approach has been used by Bonnal et al. (1997), Mealli and Pudney (2003) and Gilbert et al. (2001).
} 
unobserved heterogeneity. In all, as many as 133 parameter are estimated. To ease reading, the estimation results are spread over 3 different tables.

\subsection{Slope parameters}

The estimates of the slope parameters of the transitions that occurred after the initial spell, i.e. $\beta_{k l}$, are reported in Table 4 . The top line identifies the transition. The magnitude of the estimates can not be interpreted as marginal effects due to the highly non-linear nature of the model. On the other hand, the sing of the parameter estimates indicates the direction of the marginal effect on the hazard function.

Older recipients are found to have lower exit rates in each transition, except perhaps for $\mathrm{AESE} \rightarrow \mathrm{AE}$ (column 9). In other words they tend to have longer spells, irrespective of the state in which they are observed. Schooling increases the transitions out of both SA and Off-SA, which translates into shorter spells. More schooling is also associated with longer AE spells. The net impact of schooling on the reliance on SA can thus not be determined from inspection of the parameter estimates. This can only be ascertained through simulations of individual histories (see Section 4.3).

According to the table, there are hardly any statistically significant differences between male and female recipients as well as between Canadian-born and immigrants. On the other hand, having more children increases the duration of Off-SA, SA and AE spells. Finally, recipients residing in the Greater Montreal area have lower transition rates into AE. This is consistent with the probit regression of Table 3. Incidentally, the impact of age and schooling on the transition rates into $\mathrm{AE}$ are qualitatively similar to those of the probit regression. Likewise, in both tables Born in Canada, Gender and residing in Montreal hardly have any impact on AE.

The next panel of the table reports the impact of past AE participation on SA and OffSA spells. The first line focuses on the impact of incomplete participation. The dummy 
variable Incomplete equals 1 as soon as eligibility is lost or as soon as the program window ends and time spent in AE is less than 36 months. Early termination may result from a low attachment to the labour market. It may also result from the loss of SA eligibility due to a change in marital status. Likewise, early termination does not necessarily imply longer subsequent SA spells and/or shorter Off-SA spells. The limited work experience that was gained during participation may still be beneficial in the post-participation period. Because we use administrative data, we do not know that exact status of a participant who has left AE for Off-SA and his status as she eventually moves back into SA, if at all. The second line focuses on completed spells. ${ }^{22}$ The parameters measure the impact of AE on the transitions between SA and Off-SA once participation has reached the time limit. The impact of complete participation can not be signed unambiguously a priori. Given their limited skills, participants may find it difficult to receive attractive wage offers. Their participation in AE may be tied to a job that conceivably offered very little in terms of skills enhancement. The loss of the wage subsidy at the end of the eligibility period may induce them to move back to SA and behave like non-participants. ${ }^{23}$ The third line measures the number of elapsed months in year 2001 before entering AE. Those who enter early may have different unobservable characteristics from those who enter late. These differences can in principles be captured by the unobserved heterogeneity parameters, but is best to approximate them directly through a proxy variable.

The parameter estimates tell an interesting story. To start with, early termination of AE has a negative effect on the transition rates into SA and a positive one on transitions into Off-SA. Thus participants who leave the program prematurely will spend on average a greater proportion of time off SA than non-participants. Program completion yields similar results although the parameter estimates are somewhat smaller in absolute value. Finally, the last line of the panel shows that those who started late in 2001 tend to have shorter Off-SA $\rightarrow$ SA spells

\footnotetext{
${ }^{22}$ Only 197 AE spells were ongoing in December 2005. Furthermore, only 1,019 participants remained in AE for 36 months $(26.7 \%)$.

${ }^{23}$ This is precisely what was found in the SSP experiment. See Card and Hyslop (2005).
} 
and longer $\mathrm{SA} \rightarrow$ Off-SA spells, thus supporting the idea that they may constitute a distinct group. ${ }^{24}$

The last line of the table reports the loading factors, i.e. $\theta_{k}^{1}$ and $\theta_{k}^{2}$ from equation (9). Recall that these parameters are origin-specific and affect the exit rate from a given state. To ease interpretation, we report the correlation matrix that is implicitly defined by these parameters [see equation (10)] for the intermediate spells in Table 5. All the correlations are statistically significant. It is found that, conditional on observed characteristics $X$, individuals who are likely to have long Off-SA spells are also likely to have long SA spells. This is consistent with the idea that some have frequent short spells while other have fewer but longer spells in each state. The high correlation coefficients between AE on one hand and SA and Off-SA on the other hand suggest that participants in AE are a self-selected group.

The parameter estimates of $\beta_{k l}^{*}$, i.e. the slopes of the initial spells, are reported in columns (3)-(5) of Table 6 . They are qualitatively similar to $\beta_{k l}$, with only a few exceptions. Indeed, nearly the same parameter estimates are statistically significant in both Tables 4 and 6 , and except for the effect of age on the $\mathrm{SA} \rightarrow$ Off-SA transition, all share the same sign. On the other hand, the magnitude of the parameter estimates differ substantially between the two tables. This underlines the importance of accounting for the left-truncated spells. Imposing $\beta_{k l}$ and $\beta_{k l}^{*}$ to be the same would likely result into biased parameter estimates.

The first column of the Table 6 reports the parameters of the initial state logit model. The parameters must be interpreted as the impact of the associated variables on the probability of being in SA in January 2000 relative to being in Off-SA. According to the table, the probability of being initially on SA increases with age, being female, having more children, being born in Canada, and living in Montreal. Not surprisingly, more schooling increases the probability of being off the rolls. The second column of the table reports the results of fitting a simple logit

\footnotetext{
${ }^{24}$ Although not reported for the sake of brevity, the regression also includes a series of year dummy variables to avoid confounding start date and business cycle effects.
} 
model on the exit route once the grace period ends. Unfortunately, the model is incapable of predicting the type of transition as only the parameter associated with age is statistically significant. ${ }^{25}$

\subsection{Transition intensity functions}

Table 7 reports the shape parameter of the transition intensity functions. The top panel reports the parameter estimates of $\alpha_{l} *$ on the left-hand side and $\alpha_{l}$ on the right-hand side. The bottom panel is similarly divided with $\kappa_{l}^{*}$ on the left-hand side and $\kappa_{l}$ on the right-hand side. Figure 5 plots various transition intensity functions for intermediate spells based on the parameter estimates of Tables 4 and 7 . The functions are plotted for the average-modal individual in our sample. ${ }^{26}$ The flexibility of the log-logistic specification is readily apparent from these figures. The transitions between SA and Off-SA are drawn according to the participation status in AE. We distinguish between non-participation, incomplete participation and complete participation. The figure on the left hand-side depicts the transition rates between Off-SA and SA. Non-participants have the highest transition rates, followed by those who remained in the program for 36 months. Individuals who left AE early have the lowest transition rates. ${ }^{27}$

The figure on the right-hand side focuses on the transitions between SA and Off-SA. The simulated transition intensities present interesting features. First, the profiles are nonmonotonic. The exit rates increase in the first few months and slowly decrease past 6 or 7 months. A similar pattern has been found in a number of papers that have looked at the duration of welfare spells in Quebec [see e.g. Drolet, Fortin and Lacroix (2004)]. Second, early program drop-outs have the highest transition rates between SA and Off-SA followed by

\footnotetext{
${ }^{25}$ The loading factors of the initial condition logit and the grace period logit are assumed to be the same to help identify the parameter estimate, as there are few censored GP observations.

${ }^{26}$ The average-modal individual is female, born in Canada, lives in Montreal, has 1.5 children and 10.5 years of schooling.

${ }^{27}$ The possibility that some may have lost eligibility due to a change in their marital status, or because they have moved to another province can not be ruled out.
} 
Figure 5: Simulated Transition Intensities - Fresh Spells
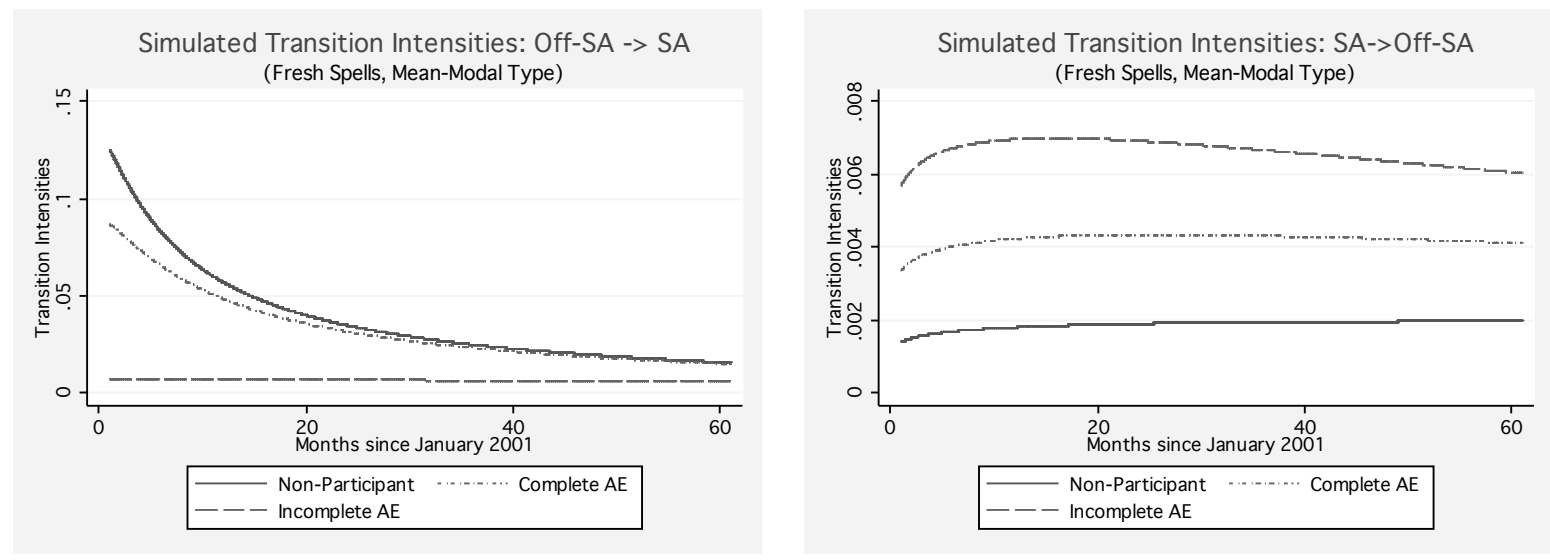

participants who spent 3 years on AE. Non-participants have by far the lowest exit rates from SA.

\subsection{Simulation Strategy}

Figure 5 suggests that AE has a positive impact on the time spent Off-SA and a negative one on time spent on SA. The figures are drawn for a mean-modal individual and neglects observed and unobserved heterogeneity. To better understand the impact of AE on the labour market dynamics it is best to turn to simulations. We generate 1,000 six-year work histories via stochastic simulations of the model. These are summarized by computing the average proportion of time spent in each of the four potential states we have considered. To control for endogenous participation in $\mathrm{AE}$, we set the random variables to their mean value (zero). The first set of simulations explores the effects of the covariates by considering slightly different characteristics from the baseline mean-modal individual. The second set focuses on the unobserved heterogeneity. This time we simulate the work history of the baseline individual but vary the random components $\xi_{1}$ and $\xi_{1}$ [see equation (9)]. 
The algorithm works as follows. The parameters of the initial condition logit are used to determine the initial state. Conditional on the initial state, we next calculate the duration of the three potential transitions (Off-SA $\rightarrow \mathrm{SA}, \mathrm{SA} \rightarrow \mathrm{Off}-\mathrm{SA}, \mathrm{SA} \rightarrow \mathrm{AE}$ ) and select the shortest. ${ }^{28}$ The $\mathrm{SA} \rightarrow \mathrm{AE}$ transition must be the shortest and occur between months 12 and 24 to be selected, as prescribed by the program. Once the transition type is determined, the parameter estimates of the subsequent spells are used to determine the next transitions until the simulated history spans a total of six years, with the last spell censored.

Table 8 reports the main findings. The top panel reports the effect of changing the age of the benchmark individual while maintaining the other characteristics constant. As the individual ages, the mean duration of Off-SA spells increases significantly while that of the SA spells remains relatively stable. As a result, the proportion of time on SA decreases slightly. Interestingly, the model predicts a participation rate of approximately $4.5 \%$, a figure slightly below the observed rate. Finally, the number of spells over the course of six years is insensitive to variations in age. The second panel of the table focuses on education. We vary the number of years of schooling from 10 to 18. High-school completion entails 12 years of schooling while a university degree more or less corresponds to 17 or 18 years. The simulations show that the duration of SA and Off-SA spells decrease with schooling. As schooling increases individuals transit more rapidly between the two states but the overall proportion of time spent in SA decreases by the same amount as was found for age. Similar findings apply when the number of children increases. In the latter case, the predicted participation rates in AE are very close to the observed rate, as expected.

While the above changes appear to be relatively small, they need be put into perspective. Recall that only $7.4 \%$ of SA recipients participate in AE and those who took-up AE might be a self-selected group among SA recipients. To look further into this issue, we simulate the likely

\footnotetext{
${ }^{28}$ We sample from the type I extreme value for the logit parts of the model, and from the distribution of the latent duration for the transition part. The inverse of the relevant cumulative density function is evaluated using uniform pseudo-random numbers.
} 
situation of our benchmark individual in the absence of the AE program. Such a counterfactual is obtained by eliminating the transitions into $\mathrm{AE}$ and by setting the random components to their mean value to avoid the problems of endogenous selection. Table 9 reports the results of simulating the work histories by educational attainment with and without AE. In the world with $\mathrm{AE}$, we only consider spells that occur after the end of $\mathrm{AE}$ when computing the mean durations. Panels (A) and (B) of Table 9 report the simulation results. The difference between the two are shown in panel $(\mathrm{C})$. In general, it is found that the AE program increases the duration of Off-SA spells by anywhere between .1 month to 1.5 months. Likewise, the program is found to decrease the average duration of SA spells from a minimum of 1.5 and up to 4.2 months in a non-monotonically fashion. There is thus considerable heterogeneity in the impact of the program.

The above simulations are all conducted under the assumption that the unobserved heterogeneity components are fixed at their mean value of zero and are cast within a six-year time frame. The model can also be used to simulate the sensitivity of the work history with respect to the unobserved heterogeneity. We once again consider our representative individual and investigate the consequences of varying the unobserved heterogeneity associated with Off-SA between -1 and 1 standard errors around its mean. Rather than simulating the work history over a six-year time frame, we focus on the duration of fresh SA and Off-SA spells conditional on past AE status. We do this simply by letting the relevant dummy variables equal one or zero as need be. Figure 6 depicts the expected duration of both SA and Off-SA spells. Recall from Table 5 that the unobserved heterogeneity components between SA and Off-SA are positively correlated and that the components are origin-specific. Because $\nu_{k}$ does not enter linearly in the hazard function [see equation (5)] the relation between expected duration in a given state and $\nu_{k}$ need not be positive or linear. As shown, an increase in the unobserved heterogeneity increases the duration of Off-SA spells of AE participants dramatically while 
Figure 6: Expected Duration of Fresh Spells, by Heterogeneity Group
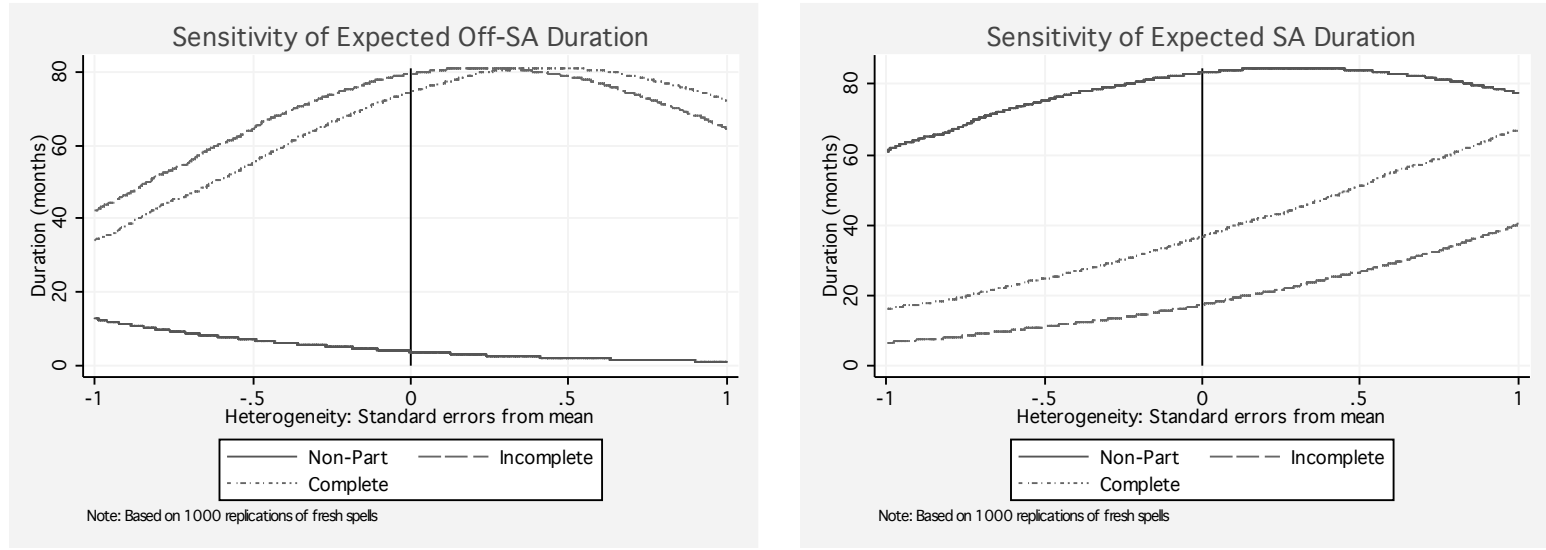

decreasing slightly that of the non-participants. Non-participants have by far the shortest expected duration, followed by complete and incomplete participation, respectively.

The right-hand side figure shows that as the value of the Off-SA-specific heterogeneity component increases, the expected duration of SA spells increases at a different rate for the 3 groups of recipients. At the mean value, non-participants are expected to have spells whose duration lasts approximately 80 months. As stressed earlier, nearly $46 \%$ of the individuals in our sample who were receiving SA payments in January 2000 had uninterrupted spells in December 2005, i.e. 72 months later. Interestingly, according to the parameter estimates the duration of SA spells of non-participants is relatively insensitive to variations in unobserved heterogeneity. On the other hand, the expected duration of participants is quite sensitive to unobserved factors but always remains well below that of the non-participants. 


\section{Conclusion}

Back in December 2001, the Quebec government implemented the so-called "Action Emploi" (AE) program for a trial period of a single year. The program was directly inspired by the SelfSufficiency Project and aimed at making work pay for long-term social assistance recipients. $\mathrm{AE}$ offered a generous wage subsidy for up to three years to those who left social assistance (SA) within twelve months to take a full-time job. Very little research has looked into the impact of the program on the employment history of the targeted population. Yet, based on little empirical evidence a slightly modified version of the program was implemented on a permanent basis in May 2008.

Despite the program's generosity, only $7.4 \%$ of eligible individuals claimed benefits. From an evaluation perspective, the possibility that the participants constitute a highly selected group must be addressed rigorously. Indeed the impact of the temporary AE program may not translate to a permanent program if participants in the latter differ systematically from those of the former. The purpose of the paper is precisely to investigate the impact of the temporary AE program while addressing the potential self-selection issue. We do this by focusing on the transitions on the labour market starting one year prior to the implementation of the program and up until the end of 2005. Our empirical strategy relies on a multi-state multi-episode transition model. The model accounts for left-censoring, for the initial conditions problem as

well as for the fixed duration of the "grace period" during which participants were entitled not to meet the program's employment requirements. The endogeneity of the participation status is accounted for by treating $\mathrm{AE}$ as a distinct state and by allowing correlated unobserved factors and observed characteristics to affect participation.

Our results show that AE has indeed increased the duration of Off-SA spells and decreased the duration of SA spells. The results vary according to whether participation was interrupted early or not. There is also some evidence that the response to the program varies considerably 
with the unobserved individual characteristics. Inasmuch as these results properly correct for self-selection into AE, it is likely that the permanent program will generate positive results. 


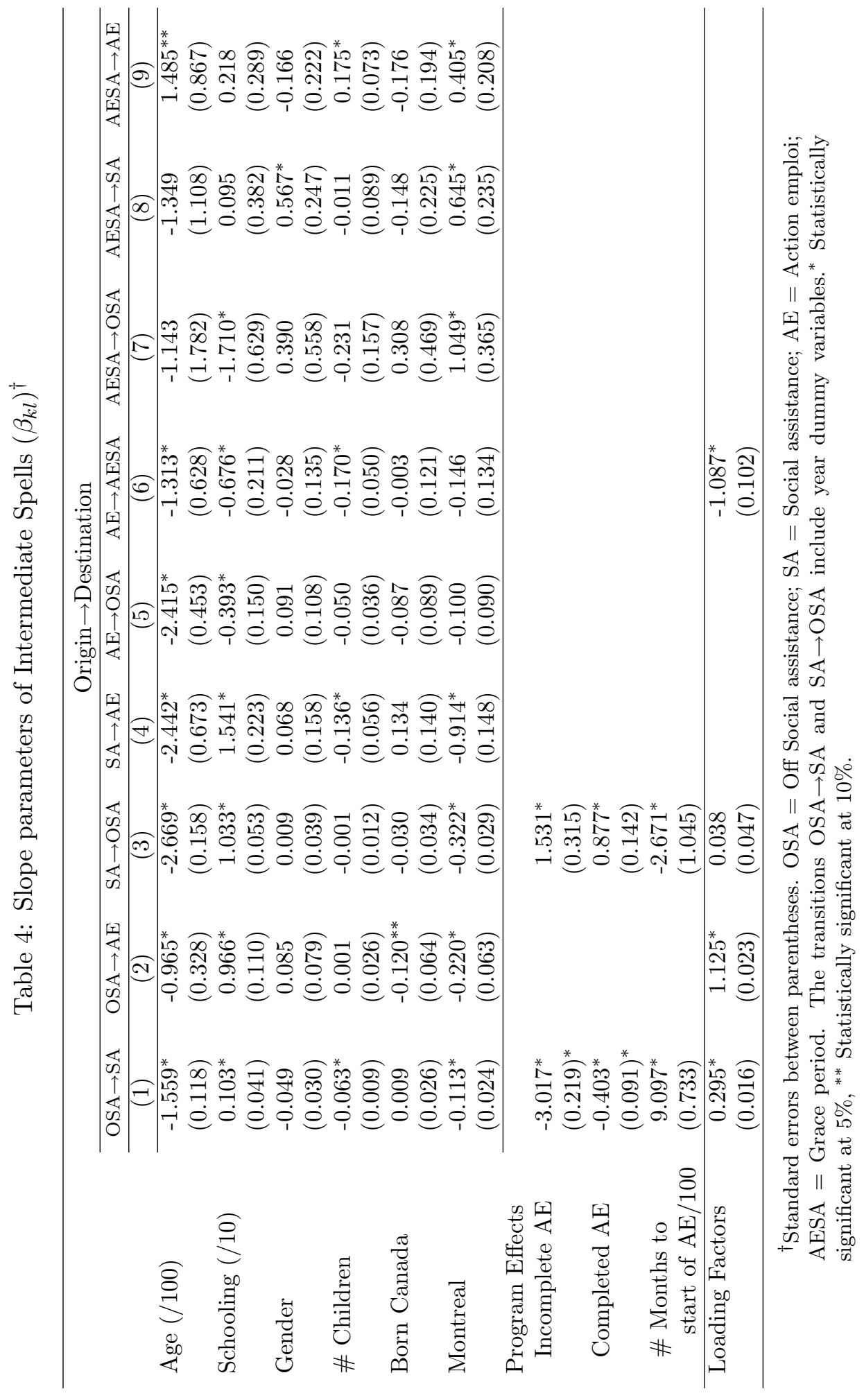


Table 5: Correlation Matrix: Intermediate spells ${ }^{\dagger}$

\begin{tabular}{c|ccc}
\hline & SA & EA & AESA \\
\cline { 2 - 4 } OSA & $0.905^{*}$ & $0.320^{*}$ & $-0.514^{*}$ \\
& $(0.008)$ & $(0.048)$ & $(0.042)$ \\
SA & & $0.692^{*}$ & $-0.100^{*}$ \\
& & $(0.036)$ & $(0.047)$ \\
AE & & & $0.649^{*}$ \\
& & & $(0.044)$ \\
\hline
\end{tabular}

* Statistically significant at $5 \%$

** Statistically significant at $10 \%$.

Table 6: Slope Parameters of Initial Condition, Grace Period and Initial Spell ${ }^{\dagger}$

\begin{tabular}{lcc|ccc}
\hline & \multicolumn{5}{c}{ Origin $\rightarrow$ Destination } \\
\cline { 2 - 6 } & $\begin{array}{c}\text { Logit } \\
\text { Initial } \\
\text { Condition }\end{array}$ & \begin{tabular}{c} 
Logit \\
Grace \\
\cline { 2 - 6 } Period
\end{tabular} & OSA $\rightarrow$ SA & SA $\rightarrow$ OSA & SA $\rightarrow$ AE \\
\cline { 2 - 6 } Age $(/ 100)$ & $6.539^{*}$ & $2.621^{* *}$ & $-0.304^{*}$ & 1.313 & $-0.977^{*}$ \\
Schooling $(/ 10)$ & $(0.190)$ & $(1.525)$ & $(0.142)$ & $(0.283)$ & $(0.441)$ \\
& $-0.470^{*}$ & 0.585 & $0.414^{*}$ & -0.045 & $0.868^{*}$ \\
Gender & $(0.058)$ & $(0.540)$ & $(0.053)$ & $(0.106)$ & $(0.160)$ \\
& $0.415^{*}$ & 0.052 & -0.021 & 0.063 & 0.018 \\
\# Children & $(0.053)$ & $(0.385)$ & $(0.039)$ & $(0.080)$ & $(0.108)$ \\
Born Canada & $0.383^{*}$ & -0.127 & $-0.038^{*}$ & $-0.057^{*}$ & -0.009 \\
Montreal & $(0.019)$ & $(0.137)$ & $(0.014)$ & $(0.028)$ & $(0.042)$ \\
& $0.288^{*}$ & -0.194 & -0.022 & 0.073 & 0.131 \\
& $(0.048)$ & $(0.362)$ & $(0.034)$ & $(0.068)$ & $(0.097)$ \\
\hline Loading Factors & $0.224^{*}$ & 0.655 & $-0.099^{*}$ & $-0.108^{* *}$ & $-0.537^{*}$ \\
& $(0.044)$ & $(0.405)$ & $(0.030)$ & $(0.061)$ & $(0.088)$ \\
\hline
\end{tabular}

${ }^{\dagger}$ Standard errors between parentheses. OSA = Off Social assistance; SA = Social assistance; $\mathrm{AE}=$ Action emploi; $\mathrm{AESA}=$ Grace period. ${ }^{*}$ Statistically significant at $5 \%,{ }^{* *}$ Statistically significant at $10 \%$. 
Table 7: Log-Logistic Shape Parameters

\begin{tabular}{|c|c|c|c|c|c|c|c|}
\hline \multirow[b]{3}{*}{ Origin } & \multicolumn{7}{|c|}{ Destination } \\
\hline & \multicolumn{3}{|c|}{ Initial spell } & \multicolumn{4}{|c|}{ Subsequent spells } \\
\hline & Off-SA & $\mathrm{SA}$ & $\mathrm{AE}$ & Off-SA & $\mathrm{SA}$ & $\mathrm{AE}$ & GP \\
\hline & \multicolumn{7}{|c|}{$\alpha_{j k}$} \\
\hline Off-SA & \multicolumn{3}{|c|}{$\begin{array}{c}2.053^{*} \\
(0.043)\end{array}$} & \multicolumn{2}{|r|}{$\begin{array}{c}1.053^{*} \\
(0.123)\end{array}$} & $\begin{array}{c}0.777^{*} \\
(0.105)\end{array}$ & \\
\hline $\mathrm{SA}$ & $\begin{array}{c}2.467^{*} \\
(0.016)\end{array}$ & & $\begin{array}{c}2.989^{*} \\
(0.221)\end{array}$ & $\begin{array}{c}1.111^{*} \\
(0.063)\end{array}$ & & $\begin{array}{c}0.793^{*} \\
(0.222)\end{array}$ & \\
\hline $\mathrm{AE}$ & & & & $\begin{array}{c}2.268^{*} \\
(0.047)\end{array}$ & & & $\begin{array}{c}0.759^{*} \\
(0.140)\end{array}$ \\
\hline \multirow[t]{3}{*}{$\mathrm{GP}^{\dagger}$} & & & & \multicolumn{4}{|c|}{$\begin{array}{c}2.070^{*} \\
(0.111) \\
\end{array}$} \\
\hline & \multicolumn{7}{|c|}{ Destination } \\
\hline & \multicolumn{3}{|c|}{ Initial spell } & \multicolumn{4}{|c|}{ Subsequent spells } \\
\hline \multirow[t]{2}{*}{ Origin } & Off-SA & $\mathrm{SA}$ & $\mathrm{AE}$ & Off-SA & $\mathrm{SA}$ & $\mathrm{AE}$ & GP \\
\hline & \multicolumn{7}{|c|}{$\kappa_{j k}($ see table note $)$} \\
\hline Off-SA & & $\begin{array}{l}-5.251^{*} \\
(0.192)\end{array}$ & & & $\begin{array}{l}-1.386^{*} \\
(0.080)\end{array}$ & $\begin{array}{l}-6.344^{*} \\
(0.202)\end{array}$ & \\
\hline SA & $\begin{array}{l}-8.330^{*} \\
(0.094)\end{array}$ & & $\begin{array}{r}-14.709^{*} \\
(0.951)\end{array}$ & $\begin{array}{l}-6.719^{*} \\
(0.094)\end{array}$ & & $\begin{array}{l}-9.365^{*} \\
(0.442)\end{array}$ & \\
\hline $\mathrm{AE}$ & & & & $\begin{array}{l}-5.763^{*} \\
(0.279)\end{array}$ & & & $\begin{array}{l}-2.817^{*} \\
(0.353)\end{array}$ \\
\hline $\mathrm{GP}^{\dagger}$ & & & & & $\begin{array}{l}-3.6 \\
(0.4\end{array}$ & $\begin{array}{l}86^{*} \\
34)\end{array}$ & \\
\hline
\end{tabular}

$\dagger$ The parameter is constant accross states of origin.

Note: All the $\kappa_{j k}$ parameters are in natural logarithms to ease reading. 
Table 8: Simulation Results: Observed Heterogeneity ${ }^{\dagger}$

\begin{tabular}{|c|c|c|c|c|c|}
\hline & \multicolumn{5}{|c|}{ Age } \\
\hline & 20 & 30 & 35 & 40 & 50 \\
\hline Mean duration Off-SA & 15.4 & 16.9 & 18.5 & 17.9 & 19.8 \\
\hline Mean duration SA & 27.3 & 27.8 & 28.8 & 29.0 & 28.8 \\
\hline$\%$ Participants & 4.5 & 4.2 & 4.3 & 5.2 & 4.3 \\
\hline$\%$ time off SA & 28.7 & 29.7 & 30.4 & 28.9 & 30.9 \\
\hline$\%$ time on $\mathrm{SA}$ & 69.7 & 69.1 & 68.3 & 69.3 & 67.6 \\
\hline$\%$ time on $\mathrm{AE}$ & 1.5 & 1.2 & 1.3 & 1.8 & 1.5 \\
\hline \multirow[t]{3}{*}{ Average \# Spells } & 3.2 & 3.0 & 2.8 & 2.8 & 2.8 \\
\hline & \multicolumn{5}{|c|}{ Education } \\
\hline & 10 & 12 & 14 & 16 & 18 \\
\hline Mean duration Off-SA & 18.0 & 17.3 & 17.8 & 17.7 & 16.4 \\
\hline Mean duration SA & 29.2 & 28.4 & 27.2 & 26.0 & 25.4 \\
\hline$\%$ Participants & 5.7 & 5.4 & 6.1 & 4.9 & 4.3 \\
\hline$\%$ time off SA & 29.1 & 29.0 & 31.1 & 32.9 & 31.7 \\
\hline$\%$ time on $\mathrm{SA}$ & 68.8 & 69.0 & 66.6 & 65.4 & 66.5 \\
\hline$\%$ time on $\mathrm{AE}$ & 2.1 & 1.9 & 2.3 & 1.7 & 1.8 \\
\hline \multirow[t]{3}{*}{ Average \# Spells } & 2.9 & 3.0 & 3.0 & 3.1 & 3.3 \\
\hline & \multicolumn{5}{|c|}{ \# of Children } \\
\hline & 1 & 2 & 3 & 4 & 5 \\
\hline Mean duration Off-SA & 17.4 & 18.5 & 18.7 & 18.6 & 19.4 \\
\hline Mean duration SA & 28.3 & 28.0 & 28.2 & 28.0 & 28.7 \\
\hline$\%$ Participants & 5.6 & 5.3 & 6.6 & 6.3 & 4.6 \\
\hline$\%$ time off SA & 29.6 & 30.9 & 30.3 & 31.3 & 31.4 \\
\hline$\%$ time on $\mathrm{SA}$ & 68.4 & 67.4 & 67.6 & 66.5 & 67.0 \\
\hline$\%$ time on $\mathrm{AE}$ & 2.0 & 1.7 & 2.1 & 2.2 & 1.6 \\
\hline Average \# Spells & 3.0 & 2.9 & 2.9 & 2.9 & 2.8 \\
\hline
\end{tabular}

$\dagger$ Based on 1000 replications, average-modal individual 
Table 9: Simulation Results: Hypothetical Individual With and Without $\mathrm{AE}^{\dagger}$

\begin{tabular}{|c|c|c|c|c|c|}
\hline & \multicolumn{5}{|c|}{ (A) Education with $A E$} \\
\hline & 10 & 12 & 14 & 16 & 18 \\
\hline Mean duration Off-SA & 18.0 & 17.3 & 17.8 & 17.7 & 16.4 \\
\hline \multirow[t]{3}{*}{ Mean duration SA } & 29.2 & 28.4 & 27.2 & 26.0 & 25.4 \\
\hline & \multicolumn{5}{|c|}{ (B) Education without $A E$} \\
\hline & 10 & 12 & 14 & 16 & 18 \\
\hline Mean duration Off-SA & 17.3 & 17.2 & 16.3 & 16.3 & 16.0 \\
\hline \multirow[t]{3}{*}{ Mean duration SA } & 30.7 & 31.2 & 31.4 & 29.8 & 29.6 \\
\hline & \multicolumn{5}{|c|}{ Difference between $(A)$ and $(B)$} \\
\hline & 10 & 12 & 14 & 16 & 18 \\
\hline Mean duration Off-SA & 0.7 & 0.1 & 1.5 & 1.4 & 0.4 \\
\hline Mean duration SA & -1.5 & -1.8 & -3.2 & -3.8 & -4.2 \\
\hline
\end{tabular}




\section{References}

Bonnal, L., D. Fougère, and A. Sérandon (1997) 'Evaluating the impact of French employment policies on individual labour market histories.' The Review of Economics Studies 64(4), 683-718

Brouillette, Dany, and Guy Lacroix (2010) 'Heterogeneous treatment and self-selection in a wage subsidy experiment.' Forthcoming, Journal of Public Economics

Card, D., and D.R. Hyslop (2005) 'Estimating the effects of a time-limited earnings subsidy for welfare leavers.' Econometrica

Doiron, D., and T. Gorgens (2008) 'State dependence in youth labor market experiences, and the evaluation of policy interventions.' Journal of Econometrics 145, 81-97

Drolet, S., B. Fortin, and G. Lacroix (2004) 'Welfare benefits and the duration of welfare spells: Evidence from a natural experiment in Canada.' Journal of Public Economics 88(7-8), 1495-1520

Eberwein, C, J. C. Ham, and R. J. LaLonde (2002) 'Alternative methods of estimating program effects in event history models.' Labour Economics 9, 249-278

Gilbert, L., T. Kamionka, and G. Lacroix (2001) 'Les effets des dispositifs publics de retour à l'emploi destinés aux jeunes hommes défavorisés au Québec.' Économie et Statistique $345,55-94$

Gouriéroux, C., and A. Monfort (1996) Simulation-Based Econometric Methods Core Lectures (Oxford University Press)

Gourriéroux, C., and A. Monfort (1991) 'Simulation based econometrics in models with heterogeneity.' Annales d'économie et de statistique 20(1), 69-107

Gritz, R.M. (1993) 'The impact of training on the frequency and the duration of employment.' Journal of Econometrics 57, 21-51

Ham, J.C., and R.J. LaLonde (1996) 'The effect of sample selection and intitial conditions in duration models: Evidence from experimental data on training.' Econometrica 64(1), 175-205

Ham, J.C., and S.A. Rea (1987) 'Unemployment insurance and male unemployment duration in Canada.' Journal of Labor Economics pp. 325-353

Harknett, K., and L. A. Gennetian (2001) 'How an earnings supplement can affect the marital behaviour of welfare recipients: Evidence from the self-sufficiency project.' Working Paper, SRDC

Heckman, J., and B. Singer (1984) 'A method for minimizing the distributional assumptions in econometric models for duration data.' Econometrica pp. 271-320

Heckman, J.J., R.J. LaLonde, and J.A. Smith (1999) 'The economics and econometrics of active labor market programs.' In Handbook of Labor Economics, ed. O. Ashenfelter and Eds. D. Card (North-Holland) chapter

Kamionka, T. (1998) 'Simulated maximum likelihood estimation in transition models.' Econometrics Journal 1, C129-C153

Laroque, G., and B Salanié (1993) 'Simulation-based estimation of models with lagged latent variables.' Journal of Applied Econometrics 8, S119-S133 
Lawless, J.F. (2003) 'Event history analysis and longitudinal surveys.' In Analysis of Survey Data, ed. R.L. Chambers and C.J. Skinner (John Wiley and Sons) chapter 15, pp. 221-243 Lise, Jeremy, Shannon Seitz, and Jeffrey A. Smith (2005) 'Equilibrium policy experiments and the evaluation of social programs.' Queen's University, WP 1076

Mealli, F., and S. Pudney (2003) 'Applying heterogenous transition models in labour economics: The role of youth training in labour market transitions.' In Analysis of Survey Data, ed. R.L. Chambers and C.J. Skinner (John Wiley and Sons) chapter 16, pp. 245-274 Mealli, F., S. Pudney, and J. Thomas (1996) 'Training duration and post-training outcomes: A duration-limited competing risks model.' Economic Journal 106(435), 422-433

Michalopoulos, C., D. Card, L. A. Gennetian, K. Harknett, and P. K. Robins (2000) 'The self-sufficiency project at 36 months: Effects of a financial work incentive on employment and income.' Working Paper, SRDC

Morris, P., and C. Michalopoulos (2000) 'The self-sufficiency project at 36 months: Effects on children of a program that increased parental employment and income.' Working Paper, SRDC

Quets, G., P. K. Robins, E. C. Paan, C. Michalopoulos, and D. Card (1999) 'Does SSP-Plus increase employment? the effect of adding services to the self-sufficiency project's financial incentives.' Working Paper, SRDC

Van den Berg, G.J. (1997) 'Association measures for durations in bivariate hazard rate models.' Journal of Econometrics 79(2), 221-245 